clusively on general hospitals. That this is psychiatric report have been under the innot merely a passing phase is shown, for example, by the fact that my own service, serving the Blackburn area, has already been in operation for 23 years. For present purposes I am not even commenting on whether or not these general hospital services are as good as, better, or worse than those based on mental hospitals. I am merely stating that it still seems necessary to make the more basic point that these general hospital services do in fact exist and are part of the reality of the situation.

One's experience does lead one to believe that-not surprisingly perhaps-where a mental hospital exists it will be used and justification will be found for its continuance. In an area where no mental hospital exists and where an administrative decision has been made not to utilise the services of one in proximity to the area alternative techniques will be developed for dealing with the area's psychiatric case-load. To those of us practising these alternative methods of approach (such as psychiatric day hospital care, organised industrial therapy, and community psychiatric nursing) it is nothing less than astonishing to find that, for example, 211 schizophrenics have been in Tooting $\mathrm{Bec}$ as long-stay inpatients for anything from 8 to 23 years. From data such as these I would draw the very opposite conclusions concerning the organisation of the psychiatric services from those drawn by the authors.

\section{MAURICE SILVERMAN}

Department of Psychological Medicine Queen's Park Hospital,

1 Department of Health and Social Security, Hospital Services for the Mentally Ill (HM(71) 2 Silverman, M, British Medical fournal, 1961, 2, 698. Silverman, M, International
Psychiatry, 1965, 11, 204.

Psychiatry, 1965, 11, 204.
Silverman, M, British fournal of Psychiatry, 1968, 114, 493.

5 Silverman, M, British Medical fournal, 1971, 3,

SIR,-I was interested to note that Dr Thomas Bewley and his colleagues (20 December, p 671) predict that $3 \%$ of patients in their hospital wards will still be there in 40 years and their conclusion that current Department of Health and Social Security plans for phasing out mental hospitals must be challenged.

As a result of a survey I carried out among the 1500 or so mental handicapped patients in the Stoke Park group of hospitals in 1971 I concluded that, at the rates of discharge, life expectancy, and death current in the group at the time and, assuming no further admissions, the last of our patients would leave us in the year 2041! Nothing has happened since that time to make me question the validity of that prediction and I fee that Dr Bewley's conclusion is certainly no less applicable to mental handicap hospitals. Stoke Park Hospital,
Stapleton, Bristol

W A HEATON-WARD

\section{Pharmacogenic shoplifting?}

SIR,-I am disconcerted by the fact that no fewer than five alleged supermarket shoplifters about whom I have been asked to provide a fluence of drugs at the time of the incident in the store. The drugs had in all cases been legitimately taken for a therapeutic purpose. deliberately and dishonestly tried to cheat the owners of the store by putting certain goods in their own shopping bag and offering payment only for other goods that they had placed in the special receptacle provided by the supermarket. The shoppers had seemingly made no attempt to conceal their actions, and the articles removed from the suspected person's bag had often included items seldom, if ever, used by him or her. This suggests that the state of mind of these people while shopping in the store had varied from marked absent-mindedness to mild confusion. These five constitute a relatively high proportion of my small series of shoplifters. They had previously had an unblemished record of honesty. It is noteworthy that one of them had earlier shown herself to be over-sensitive to calmative drugs, for she had on one occasion become completely confused as a result of taking a normal dose of drugs prescribed by her doctor; while another had, years earlier and passed through a phase of leaving behind in shops goods for which she had paid.

It seems not unlikely that these persons had no criminal intent but were the victims of two factors which, acting in concert, impaired their concentration sufficiently to have rendered them liable to make serious mistakes when shopping in supermarkets. The first of these factors is that they were suffering from an anxiety-depressive state, a condition prone to render the subject abnormally preoccupied. The second is that the drugs prescribed to assuage the patient's symptoms further augmented their blunted concentration.

It would appear that persons taking calmative and antidepressive drugs should be warned about the apparent danger of shopping in a supermarket while under the influence of drugs (alcohol could doubtless have a similar effect).

J TODD

Mencton, West Yorkshire

\section{Selective induction of labour}

SIR,-We read with interest the paper of Professor K O'Driscoll and others (27 December, $p$ 727) on selective induction of labour in which they state that "enthusiasm for the statistical concept of high risk in obstetric practice should be reviewed. ..." We would question whether their study of 1000 primigravidae has sufficient data to evaluate the risks in pregnancies continuing beyond term. Although they state that prolonged pregnancy was not a feature in any case of perinatal mortality, one death occurred at 41 weeks' gestation as a result of fetal hypoxia in labour. In 1970 a study of 16748 births in Glasgow reported 50 unexplained deaths in mature babies, a rate of three per 1000.1 Had Professor O'Driscoll and his colleagues studied a larger number of patients they might have encountered a greater number of potentially avoidable perinatal deaths. Furthermore, they excluded parous patients, although many of the unexplained deaths in the Glasgow study ocAt first sight the persons concerned had when under drug treatment for depression,

High Royds Hospital, curred in such women. In 1974 a second study of 10552 births in Glasgow ${ }^{2}$ has shown that unexplained deaths have fallen to 21 (two per 1000) and a rising induction rate may have contributed to this fall.

In discussing their results Professor O'Driscoll and his colleagues refer to the "disadvantages of induction" without specifying what these are. It is interesting to note that, having selected 95 of the 1000 primigravidae as demonstrating risk factors which called for induction of labour, they subsequently found it necessary to perform caesarean section in only three of these, a rate of $3 \cdot 2 \%$. Caesarean section was performed in 48 of the 905 cases in which labour was not induced, a rate of $5.3 \%$. This fall in the caesarean section rate after induction is in keeping with our own experience. ${ }^{3}$ Indeed, far from conferring an increase in perinatal or maternal morbidity, induction of labour in the Dublin study would appear to reduce them, since it was associated with no perinatal deaths, no cases of cerebral dysfunction, and only one caesarean section for fetal distress. Bearing in mind that those induced were considered to be at greatest risk of fetal hypoxia, this does not support their contention that oxytocin imposes great stress on the fetus. We also wish to question the statement that a copious flow of clear liquor at induction shows that the fetus is not in danger and the induction therefore misguided. No evidence is presented to support this claim.

Although Professor O'Driscoll and his colleagues are challenging the "statistical approach" to improving obstetric practice, this is the very approach which they themselves have used in their paper; we would suggest, however, that the sample studied is too small to produce meaningful results. Clearly more information is required both about the risks of induction of labour and about the risks of pregnancies extending beyond term. As we and others have shown, it is more profitable to conduct a detailed study of a complete population, defining the obstetric factors associated with perinatal death, than to study a number of consecutive deliveries in most of which the outcome is satisfactory and uncomplicated. A confidential inquiry into the circumstances of perinatal deaths on similar lines to the one for maternal deaths might have much to commend it.

P W HOWIE

A A Calder

G M MCILWAINE

R C L HOWAT M C MaCNAUghtoN

University Department of Obstetrics and Gynaecology, Glasgow

1 McIlwaine, G M, Macnaughton, $M \quad C$, and Richards, I D G, Health Bulletin, 1974, 32, 103. McIlwaine,

Cole, R A, Howie, P W, and Macnaughton, M C, Lancet, 1975, 1, 767 .

Joint Committee on Higher Medical

Training: enrolment and accreditation

SIR,-I write on behalf of the Joint Committee on Higher Medical Training regarding enrolment and accreditation in the relevant specialties. Enrolment will enable the JCHMT and the specialist advisory com- 